\title{
Preprocedure patient preferences and attitudes toward permanent contraceptive options
}

\author{
This article was published in the following Dove Press journal: \\ Patient Preference and Adherence \\ 13 April 2012 \\ Number of times this article has been viewed
}

\section{Hector O Chapa \\ Gonzalo Venegas}

Department of Obstetrics and Gynecology, Women's Specialty Center Dallas, Methodist Medical

Center, Dallas, TX, USA
Correspondence: Hector O Chapa Women's Specialty Center Dallas, 2042 Marydale Rd, Dallas, TX 75208, USA

Email chapamd@gmail.com
Objective: To determine patient preference for laparoscopic tubal occlusion or hysteroscopic tubal occlusion, two common sterilization interventions, and the acceptability of a postprocedure confirmation test for a hysteroscopic approach.

Participants and methods: A total of 100 patients were offered two procedures. A description of each procedure was developed and read to each patient by a research nurse on site. Patients were then asked to respond to a questionnaire concerning options. Final informed consent, procedure review, and procedural date determination were provided by a physician upon completion of the questionnaire. Patients were not allowed to change their questionnaire responses after completion. No interviewer or physician input was allowed during the questionnaire. The study was completed in English or Spanish, as per patient request, by a bilingual/fluent speaker. Physicians completing informed consent were unaware of the questionnaire responses. Patients were not financially incentivized.

Results: Of 100 participants, 93 (93\%) preferred hysteroscopic sterilization to laparoscopy. The reasons were as follows: fear of general anesthesia (24/93 [26\%]), fear of incision (25/93 [27\%]), cost $(32 / 93$ [34\%]), and time (12/93 [13\%]) to return to routine activity. All 93 viewed "office-based location" as the main advantage over laparoscopy; 88/93 (94.6\%) considered a confirmation test to be a benefit of the procedure. After informed consent was obtained, one additional patient switched from a laparoscopic decision to hysteroscopy (total=94/100); 89/94 (95\%) hysteroscopic decisions underwent hysteroscopic sterilization; 4/6 (67\%) laparoscopic decisions proceeded to that surgery. The remainder $(\mathrm{N}=7)$ cancelled due to lack of financial resources.

Conclusion: A nonincisional, office-based approach to sterilization has high patient acceptability. Patients viewed a confirmatory test for tubal occlusion as a benefit after sterilization.

Keywords: sterilization, hysteroscopy, confirmation testing, laparoscopy, patient preference

\section{Introduction}

Sterilization is the most common contraceptive method utilized by couples in the USA, with $36 \%$ of fertile women using contraception employing this method. ${ }^{1}$ About 700,000 female sterilizations are performed annually, half of which are performed within 48 hours postpartum ${ }^{2}$ and the remainder performed as interval procedures that do not occur immediately following pregnancy. ${ }^{3}$ Traditional nonhysteroscopic female sterilization techniques carry an overall complication rate of $0.9 \%-1.6 \%{ }^{4}$ Access to the abdomen is one challenge of laparoscopy, as surgical instruments must be inserted through small incisions. Access is therefore associated with injuries to the gastrointestinal tract and major blood vessels and at least $50 \%$ of these major complications occur 
prior to commencement of the intended surgery. ${ }^{5,6}$ The ability to offer female sterilization via a hysteroscopic approach not only offers a safer sterilization option but may also increase access to care due to in-office performance. ${ }^{7}$

Numerous authors have published studies on patient satisfaction and acceptability after hysteroscopic sterilization. ${ }^{8-11}$ However, a search of Medline, PubMed, and Medscape databases did not retrieve any published articles on patient preference (choice) for one method of sterilization over another when presented with clear, descriptive briefings on laparoscopic and hysteroscopic sterilization techniques. This search was not limited to the English language, and the keywords "sterilization," "laparoscopy," "hysteroscopy," and "Essure ${ }^{\circledR}$ " were employed. Although published reports were located on female patients' attitudes toward the concept of sterilization, ${ }^{12,13}$ no reports queried patients' preference for one sterilization procedure over another. Although some may assume that a nonincisional mode of therapy would be preferred over traditional laparoscopy, no published data exist to support this conclusion. We therefore sought to investigate whether a more minimally invasive method of tubal sterilization would appeal more to patients requesting permanent birth control.

\section{Participants and methods}

This research was conducted from January 2008 to March 2009. Patients referred to the Women's Specialty Center (WSC) Dallas, Texas, for permanent sterilization were invited to participate in the study, with a goal of recruiting 100 patients. The Ethical Review Board of the WSC granted approval for the investigation. Patients who agreed to participate in the study were first asked for a medical history and had their vital signs checked by a triage nurse. Following this, they were assigned to a research nurse before physician contact. Once the patient's desire for sterilization was confirmed, the research nurse proceeded to read scripted descriptions of laparoscopic tubal ligation and hysteroscopic sterilization (Essure ${ }^{\circledR}$ Hysteroscopic Sterilization System, Conceptus Inc, Mountain View, CA; see Table 1) in either English or Spanish, according to patient preference. After reading each description, the patient was allowed to reread the script before answering the study questionnaire regarding the sterilization option of choice (Figure 1). After questionnaire completion, patients were then directed to the attending physician for a formal interview, to have their history taken and a physical examination. Informed consent for sterilization was also taken at this time. Each attending physician was blinded as to whether the patient was part of the study as well as to the patient's choice of sterilization method.

Patients declining to participate in the study were directed to the attending physician after medical triage for routine history and physical examination, interview, and informed consent for sterilization.

Each attending physician at WSC routinely offers two options for permanent birth control: laparoscopic tubal occlusion with titanium clips or office-based hysteroscopic sterilization with nitinol/PET micro-inserts. Routine surgical informed consent is offered by all WSC physicians according to set office protocols. Informed consent includes type of procedure descriptions and outlines the risks and benefits, procedure, location where each respective procedure is performed - operating room versus consultants's office setting, and postoperative recovery times for all indicated procedures.

The primary outcome measured was the type of sterilization favored, based on set scripted descriptions, as well as attitudes toward a posthysteroscopic sterilization confirmation test. The secondary outcome was percent-decision concordance with the study questionnaire prephysician consult and choice of sterilization after physician interview and consent. Additionally, the percentage of patients who actually proceeded to sterilization was determined per group. Finally, compliance with posthysteroscopic sterilization confirmation testing at 12 weeks postprocedure was determined.

\section{Results}

Patients were referred from a variety of sources: $60 \%$ of referrals were from family practice groups, $15 \%$ from women's health nurse practitioner practices, $20 \%$ from community family planning clinics, and $5 \%$ of patients self-referred. Patient demographics are shown in Table 2. All patients meeting the inclusion criteria who were offered participation accepted. Our goal of 100 subjects was reached in March 2009 after beginning in January 2008. Thirty-two percent of patients requested to have their sessions in Spanish. After both surgical options were read, 93/100 (93\%) patients preferred hysteroscopic sterilization over laparoscopy, as indicated by the questionnaire results. The reasons declared were as follows: fear of general anesthesia (24/93 [26\%]), fear of incision (25/93 [27\%]), cost (32/93 [35\%]), and time to return to routine activity (12/93 [12.9\%]). All 93 viewed "office-based location" as the main advantage of hysteroscopic sterilization over laparoscopy.

Of the 93 patients who chose hysteroscopic sterilization, $88 / 93(94.6 \%)$ considered a confirmation test to be a benefit 
Table I Sterilization options offered by our physicians

\begin{tabular}{|c|c|}
\hline Option A: Laparoscopy & Option B: Hysteroscopy \\
\hline Description & Description \\
\hline $5 \mathrm{~mm}$ lens (instrument) is placed through the belly button. Gas is placed & $5 \mathrm{~mm}$ lens (instrument) is placed through your uterine cervix \\
\hline into the abdomen to see the uterus and tubes. Both tubes are clamped & (through vagina). Water is placed into the uterus to see the tubal \\
\hline and blocked from the outside. Gas and instruments are removed. & openings. The tubes are blocked from the inside. You will have \\
\hline You will be taken to recovery room for I-2 hours before release to home & $5-10$ minutes in room for recovery before release to home \\
\hline Potential risks & Potential risks \\
\hline Failure rate: $13 / 1000$ for "all laparoscopic sterilizations" at year $5^{\mathrm{a}, \mathrm{b}}$ & Failure rate: $2.6 / 1000$ for Essure ${ }^{\circledR}$ hysteroscopic sterilization \\
\hline Infection & at year $5^{\mathrm{a}, \mathrm{b}}$ \\
\hline Bleeding & Infection \\
\hline Intestine/blood vessel injury & Local/IV anesthesia risks \\
\hline \multicolumn{2}{|l|}{ General anesthesia risks } \\
\hline Location of procedure: Hospital/Day surgery & Location of procedure: Office \\
\hline Anesthesia: General & Anesthesia: Local/IV \\
\hline Incisions (cuts): Two, $5 \mathrm{~mm}$ each & Incisions (cuts): None \\
\hline After procedure confirmation test & After procedure confirmation test \\
\hline (verifies whether tubes are blocked): No & (verifies whether tubes are blocked): Yes \\
\hline Confirmation test done: No & Confirmation test done: 3 months later \\
\hline Financial: Plan co-pay deductible ${ }^{c}$ & Financial: Plan co-pay for office visit ${ }^{c}$ \\
\hline Time to heal: $3-5$ days & Time to heal: $1-2$ days \\
\hline Birth control effect ready: Same day & Birth control effect ready: 3 months $^{d}$ \\
\hline
\end{tabular}

1. Based upon the given sterilization descriptions, which do you prefer (circle choice)? Option A: Laparoscopy Option B: Hysteroscopy

2. What is the most important reason for your decision (TOP 4)? Place \#1 by the MOST important, \#2 for the next most important, etc. The higher the number, the LESS important.

Cost

Location of procedure

Type of anesthesia

Fear of anesthesia

Return to normal daily function

Fear of incision

Other reason(s):

3. Is the confirmation test to check whether the tubes are blocked a benefit?

Y Yes__ No

4. About you

(All responses to be used ONLY for research purposes. Your provider will not have the responses during your consultation.)

Age:

Ethnic background/Race: African American White Hispanic

Number of children living:

Highest grade level completed:

Are you currently working:

Past surgeries:

Do you smoke cigarettes?

What is your average annual income (circle choice)?

$<\$ 15,000.00 \$ 16,000.00-25,000.00 \quad \$ 26-35,000.00>\$ 35,000.00$ Prefer not to state

Figure I Chapa patient questionnaire. 
Table 2 Patient demographics $(\mathrm{N}=100)$

\begin{tabular}{ll}
\hline Age & Range 34-48, mean 44 \\
\hline Ethnicity & \\
African-American & $34 \%$ \\
Caucasian & $29 \%$ \\
Hispanic & $37 \%$ \\
Living children & \\
$\leq 3$ & $64 \%$ \\
$3-5$ & $32 \%$ \\
$\geq 5$ & $4 \%$ \\
Employed & Yes $93 \%$ \\
Past surgeries & Yes $16 \%$ \\
Cigarette use & Yes 7\% \\
Income level (USD\$) & \\
$<15,000.00$ & $3 \%$ \\
I6,000.00-35,000.00 & $24 \%$ \\
$>35,000.00$ & $68 \%$ \\
Not stated & $5 \%$ \\
Highest grade level completed & \\
$\leq 10$ th & $2 \%$ \\
$\leq 12$ th & $63 \%$ \\
College $<2$ years & $14 \%$ \\
College $>2$ years & $12 \%$ \\
Not stated & $9 \%$ \\
\hline
\end{tabular}

of the procedure. After physician consultation was performed and informed consent was obtained, an additional patient switched from a laparoscopic decision to hysteroscopy (thus, 94/100); 89/94 (95\%) hysteroscopic decisions proceeded to and completed sterilization; 4/6 (67\%) laparoscopic decisions proceeded to surgery. The remainder $(\mathrm{n}=7$, five in the hysteroscopic group and two in the laparoscopic group) cancelled due to lack of financial resources (co-pay funds; ie, those unable to provide their required financial portion for procedure performance).

Of the 89 hysteroscopic sterilizations performed, $87 / 89$ (97.7\%) had successful bilateral first attempt micro-insert insertions. The remaining two had initial unilateral micro-insert placement due to tubal spasm. Both underwent successful second attempts at 1 and 2 weeks after the first attempt, respectively.

\section{Discussion}

Hysteroscopic sterilization has been commercially available since 2002. Physicians recognize the advantages of hysteroscopic sterilization as being that it is nonincisional, avoids abdominal entry (which may be especially important for women with adhesions or comorbidities), can be performed as an office procedure, and allows for avoidance of general anesthesia. ${ }^{14}$ Overall, studies have demonstrated high patient satisfaction with Essure postprocedure. In a 6-year review of Essure, $96 \%-99 \%$ of patients reported satisfaction and comfort as "good" to "excellent" during follow-up visits. ${ }^{8}$ However, no peer-reviewed, published work has examined patients' attitudes or preferences for one modality or the other, in terms of offering both options in a standardized, objective format.

Our results indicate that when presented with a clear, objective, and factual description of surgical intervention options, patients - like physicians - prefer a minimally invasive alternative to traditional surgery. Our analysis has several strengths. First, as previously stated, as far as the authors are aware, this is the first attempt to determine patients' preferences for and attitudes toward sterilization techniques. Additionally, by including patient perspectives on a postoperative confirmation test, we were able to validate the assumption that such a test provides "mental reassurance" concerning reliance. We sought to eliminate interviewer bias by standardizing the initial descriptions of each procedure. Additionally, to avoid variance in message delivery, the research assistants reading each script were timed to allow for reproducible sessions. Neither of the two research assistants was involved with data tabulation or processing. Interestingly, none of the patients who chose hysteroscopic sterilization on the questionnaire altered their decision after physician consultation.

Another strength of this study it that it followed the cohort to the performance of final sterilization. This aids in validating the notion that surgical decisions actually translated into surgical performance. Interestingly, our first-attempt bilateral micro-insert placement rate (98\%) is in agreement with the US Food and Drug Administration's published rate for the Essure system (97\%). ${ }^{15}$

\section{Limitations and future directions}

This study did not include patient compliance to confirmation test completion. However, this will be the subject of our next article, a subanalysis of this cohort $(\mathrm{n}=89)$. Additionally, our cohort reflects the sociodemographic characteristics of an inner-city population. The application of these findings to other sociodemographic groups may be assumed but cannot be commented on at this time. In a 2011 report on sterilization trends, it was found that men with higher education and income had a greater prevalence of vasectomy than those less educated, while less-educated women with a lower income had the highest prevalence of tubal sterilization. ${ }^{16-18}$ However, this report by Anderson et al did not evaluate hysteroscopic sterilization as an alternative to female laparoscopic sterilization. Clearly, the option of hysteroscopic sterilization and its acceptability across income and educational backgrounds must be further described in light of the minimally invasive nature of the procedure. Additionally, we based our case study on the Essure Hysteroscopic System only. 
We cannot comment on patient attitudes toward the Adiana ${ }^{\circledR}$ Radiofrequency Hysteroscopic System (Hologic Inc, Bedford, MA), as it has not been adopted by the WSC.

In drafting our written script for each respective sterilization procedure, we sought to eliminate observer bias by providing factual, realistic, and concrete narrative descriptions of both options. ${ }^{19}$ The failure rate stated for laparoscopic tubal ligation (13/1000 at year 5) was chosen for the ease of reporting and represents a congregate figure of all laparoscopic tubal methods, based on published data. ${ }^{20}$ We acknowledge a limitation of our stated laparoscopic failure rate (Table 1), since individual laparoscopic sterilization techniques have unique and varied failure rates. ${ }^{20}$ For example, according to a US Collaborative Review of sterilization study, postprocedural pregnancy rates were highest following laparoscopic Hulka-Clemens clip sterilization (36.5 pregnancies per 1000 procedures) and lowest following unipolar coagulation and postpartum partial salpingectomy (7.5 pregnancies per 1000 procedures. ${ }^{19,20}$ Additionally, long-term failure rates were found to be closely tied to the patient's age at the time of procedure, with higher failure rates for younger patients. ${ }^{20}$ These points were not included in our written script, based on the suspicion that their inclusion may confuse those receiving the message. It was our intention to provide a reproducible and easy-tofollow text for each procedure's narrative. A final limitation of this report lies in the use of a nonvalidated questionnaire/ survey of patient preferences.

Physicians are aware of the decreased surgical morbidity that minimally invasive technologies afford. According to Kulier et al, laparoscopic sterilization, as compared with mini laparotomy, was associated with decreased operative morbidity. ${ }^{21}$ However, risks secondary to abdominal entry persist. According to the US Food and Drug Administration, the incidence of all-reported laparoscopic trocar injuries between 1997 and 2002 was 3\%.22 Penetration injury to major vessels and/or visera is the most life threatening of these injuries. Data are less complete for evaluating the risks of the hysteroscopic procedure for micro-insert placement, but the use of local anesthesia (with or without sedation) and the ability to avoid entering the peritoneal cavity are substantial safety advantages. Care must be taken to avoid potential complications, including hypervolemia and uterine perforation. In the Essure Phase II study and the pivotal trial, the latter complication occurred in $2.9 \%$ and $1.1 \%$ of procedures, respectively. ${ }^{23}$ Based on our analysis, presented here, it seems that patients are also aware of the procedural morbidity differences between sterilization options.

\section{Conclusion}

In closing, as a study, our analysis serves as a tool that strongly validates the statistical increase in hysteroscopic sterilization since $2002^{24}$ and validates the assumption that, when provided with a choice, patients - like physicians recognize the advantages and benefits of minimally invasive technologies.

\section{Disclosure}

Hector O Chapa serves as a medical consultant to Conceptus, Inc. Neither financial incentive nor direction was given for the completion of this study. Gonzalo Venegas has no conflicts of interest to declare in this work. This study was conducted independently of any corporate sponsorship or guidance. The publication fee was provided by an unrestricted educational grant from Conceptus, Inc.

\section{References}

1. Mosher WD, Martinez GM, Chandra A, Abma JC, Willson SJ. Use of contraception and use of family planning services in the United States: 1982-2002. Adv Data. 2004;350:1-35.

2. Westhoff C, Davis A. Tubal sterilization: focus on the U.S. experience. Fertil Steril. 2000;73:913-922.

3. MacKay AP, Kieke BA Jr, Koonin LM, Beattie K. Tubal sterilization in the United States, 1994-1996. Fam Plan Perspect. 2001;33: 161-165.

4. Lessard CR, Hopkins MR. Efficacy, safety, and patient acceptability of the Essure ${ }^{\mathrm{TM}}$ procedure. Patient Prefer Adherence. 2001;5: 207-212.

5. Vios GA, Temanian A, Dempster J, Laberge PY. Laparoscopic entry: a review of techniques, technologies, and complications. J Obstet Gynaecol Can. 2007;29(5):433-65.

6. Orlando R, Palatini P, Lirussi F. Needle and trocar injuries in diagnostic laparoscopy under local anesthesia: What is the true incidence of these complications? J Laparoendosc Adv Surg Tech A. 2003;13(3):181-184.

7. Arjona JE, Miño M, Cordón J, Povedano B, Pelegrin B, CasteloBranco C. Satisfaction and tolerance with office hysteroscopic tubal sterilization. Fertil Steril. 2008;90:1182-1186.

8. Connor VF. Essure: a review six years later. J Minim Invasive Gynecol. 2009;16(3):282-290.

9. Levie M, Weiss G, Kaiser B, Daif J, Chudnoff SG. Analysis of pain and satisfaction with office-based hysteroscopic sterilization. Fertil Steril. 2010;94(4):1189-1194.

10. Duffy S, Marsh F, Rogerson L, et al. Female sterilisation: a cohort controlled comparative study of ESSURE versus laparoscopic sterilisation. BJOG. 2005;112(11):1522-1528.

11. Nichols M, Carter JF, Fylstra DL, Childers M. A comparative study of hysteroscopic sterilization performed in-office versus a hospital operating room. J Minim Invasive Gynecol. 2006;13(5): $447-450$.

12. Ogedengbe OK, Giwa-osagie OF, Usifoh CA. The attitude of fertile Nigerian women to sterilization. Biol Soc. 1990;7(3):135-138.

13. Borrero S, Nikolajski C, Rodriguez KL, Creinin MD, Arnold RM, Ibrahim SA. "Everything I know I learned from my mother ... or not": perspectives of African-American and white women on decisions about tubal sterilization. J Gen Intern Med. 2009;24(3):312-319.

14. Gariepy AM, Creinin MD, Schwarz EB, Smith KJ. Reliability of laparoscopic compared with hysteroscopic sterilization at 1 year: a decision analysis. Obstet Gynecol. 2011;118(2 Pt 1):273-279. 
15. Loomis Group. Conceptus (R) receives FDA approval on Essure's bilateral placement rate to $96.9 \%$ [press release]. London: Reuters; 2010. Available from: http://www.reuters.com/article/2010/05/18/idUS226590+ 18-May-2010+BW20100518. Accessed January 21, 2012.

16. Anderson JE, Jamieson DJ, Warner L, Kissin DM, Nangia AK, Macaluso M. Contraceptive sterilization among married adults: national data on who choices vasectomy and tubal sterilization. Contraception. 2011. Epub Nov 29.

17. Borrero S, Abebe $\mathrm{K}$, Dehlendorf $\mathrm{C}$, et al. Racial variation in tubal sterilization rates: role of patient-level factors. Fertil Steril. 2011;95(1):17-22.

18. Borrero SB, Reeves MF, Schwarz EB, Bost JE, Creinin MD, Ibrahim SA. Race, insurance status, and desire for tubal sterilization reversal. Fertil Steril. 2008;90(2):272-277.

19. Bartz D, Greenburg J. Sterilization in the United States. Rev Obstet Gynecol. 2008;1(1):23-32.

20. Peterson HB, Xia Z, Wilcox LS, Tylor LR, Trussell J. Pregnancy after tubal sterilization with bipolar electrocoagulation. U.S. Collaborative Review of Sterilization Working Group. Obstet Gynecol. 1999;94:163-167.
21. Kulier R, Boulvain M, Walker DM, De Candolle G, Campana A. Minilaparotomy and endoscopic techniques for tubal sterilisation. Cochrane Database Syst Rev. 2002;(3):CD001328.

22. Fuller J, Scott W, Ashar B, Corrado J. Laparoscopic Trocar Injuries: A Report from a U.S. Food and Drug Administration (FDA) Center for Devices and Radiological Health (CDRH) Systematic Technology Assessment of Medical Products (STAMP) Committee. Silver Spring, MD: US Food and Drug Administration; 2003. Available from: http:// www.fda.gov/medicaldevices/safety/alertsandnotices/ucm197339.htm. Accessed March 27, 2012.

23. Peterson HB. Sterilization. Obstet Gynecol. 2008;111( 1):189-203.

24. Shavell VI, Abdallah MA, Shade GH, Diamond MP, Berman JM. Trends in sterilization since the introduction of Essure hysteroscopic sterilization. J Minim Invasive Gynecol. 2009;16(1):22-27.

25. Brill AI (moderator), Anderson TL, Levie MD. Hysteroscopic Sterilization. ACOG Update (web based). June 2010-July 2011;36(11).

\section{Publish your work in this journal}

Patient Preference and Adherence is an international, peer-reviewed, open access journal focusing on the growing importance of patient preference and adherence throughout the therapeutic continuum. Patient satisfaction, acceptability, quality of life, compliance, persistence and their role in developing new therapeutic modalities and compounds to optimize clinical outcomes for existing disease states are major areas of interest. This journal has been accepted for indexing on PubMed Central. The manuscript management system is completely online and includes a very quick and fair peer-review system. Visit http://www.dovepress.com/ testimonials.php to read real quotes from published authors. 